\title{
Adsorption of anionic dyes using a poly(styrene-block-4-vinylpyridine) block copolymer organogel
}

Sanjeevi Prasath Sridhar ${ }^{\dagger}$, Jacob John ${ }^{\S}$, Peter Holmqvist" ${ }^{\#}$, Ulf Olsson ${ }^{\#}$, Saravanan Chandran ${ }^{\dagger}$ and Brijitta Joseph ${ }^{\dagger, \#, *}$

†Soft Matter Laboratory, Centre for Nanoscience and Nanotechnology, Sathyabama Institute of Science and Technology, Chennai 600119, Tamil Nadu, India

${ }^{\S}$ Department of Chemical Engineering, Indian Institute of Technology Madras, Chennai-600036, Tamil Nadu, India

\#Division of Physical Chemistry, Department of Chemistry, Lund University, 221 00, Lund, Sweden

*Email: brijitta@live.com

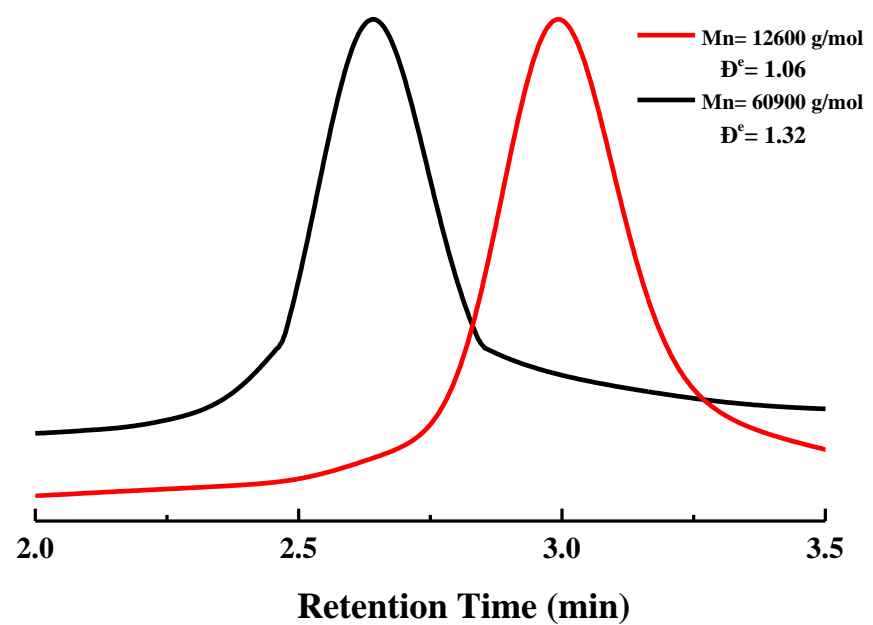

Figure S1. APC curves for the PS-CTA and PS- $b$-P4VP polymer. Red line denote PS-CTA and black line denote PS- $b$-P4VP block copolymer.

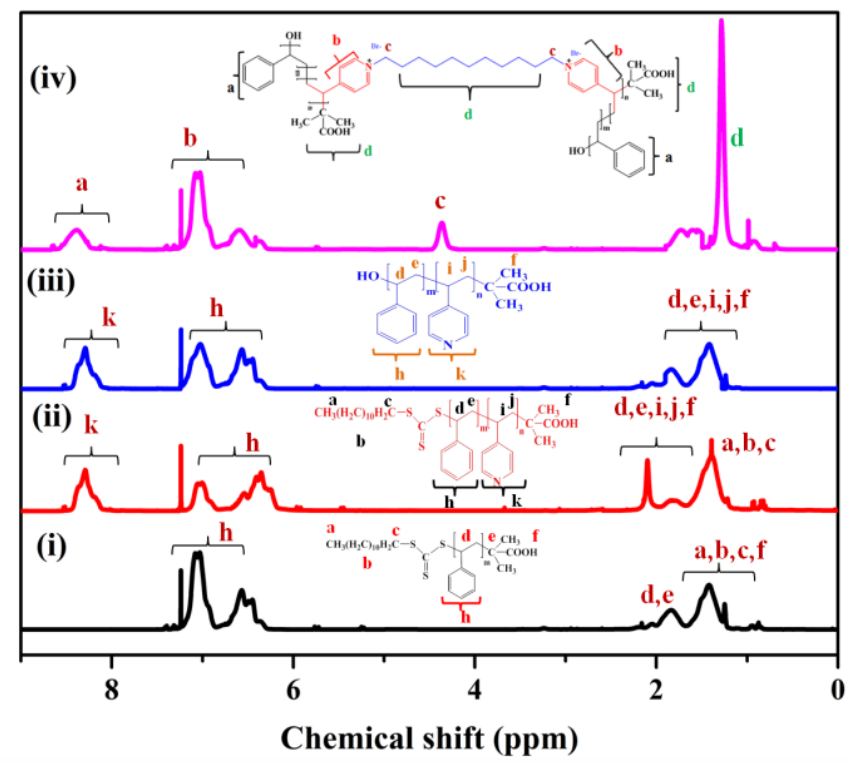

Figure S2. The ${ }^{1} \mathrm{H}$ NMR spectra of the (i) PS-CTA, (ii) PS- $b$-P4VP-CTA and (iii) PS- $b$-P4VP block copolymer (iv) PS- $b$-P4VP cross-linked organogel. 

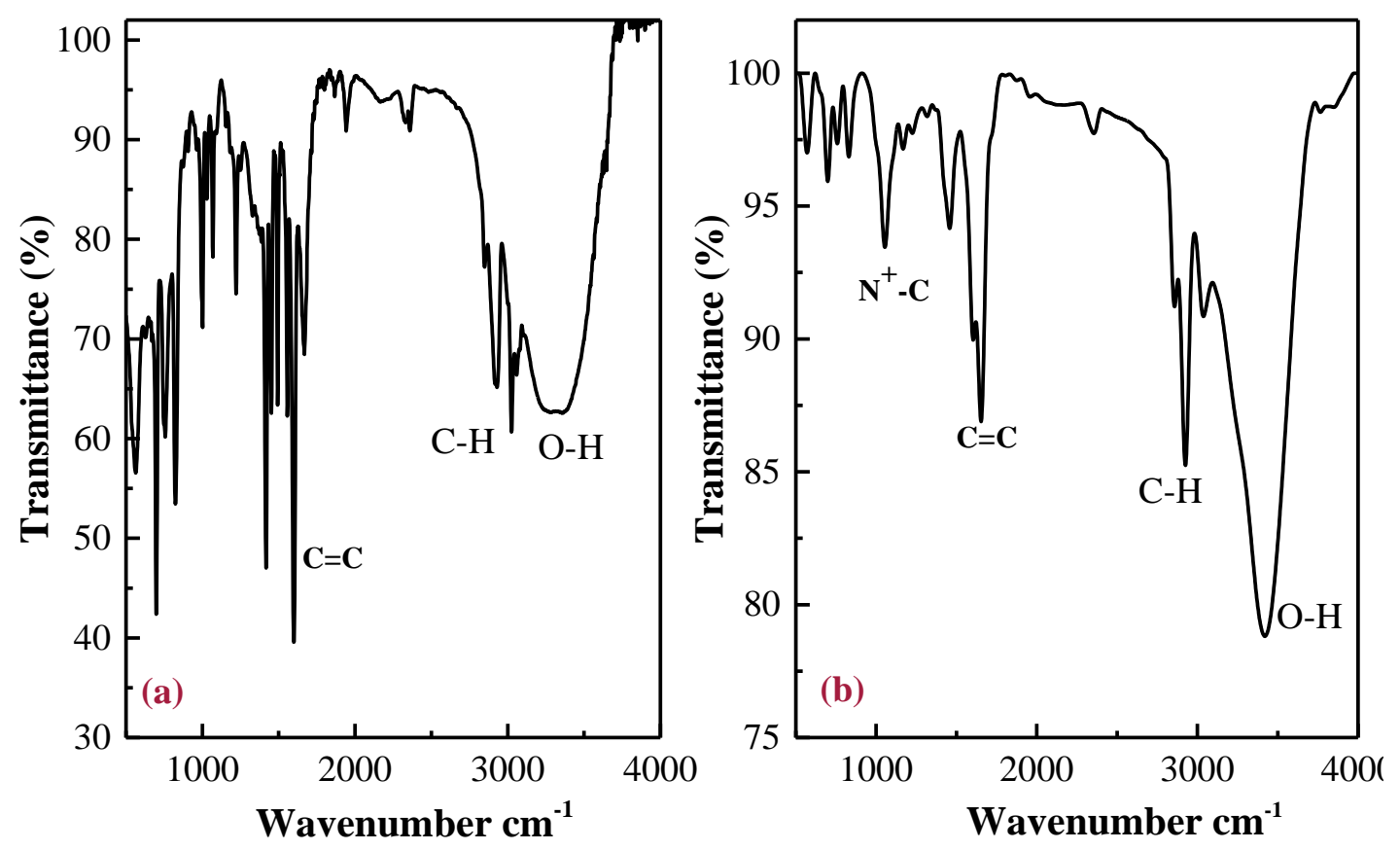

Figure S3. FTIR spectra of PS- $b$-P4VP block copolymer (a) before gelation (b) after gelation of PS$b$-P4VP organogel.

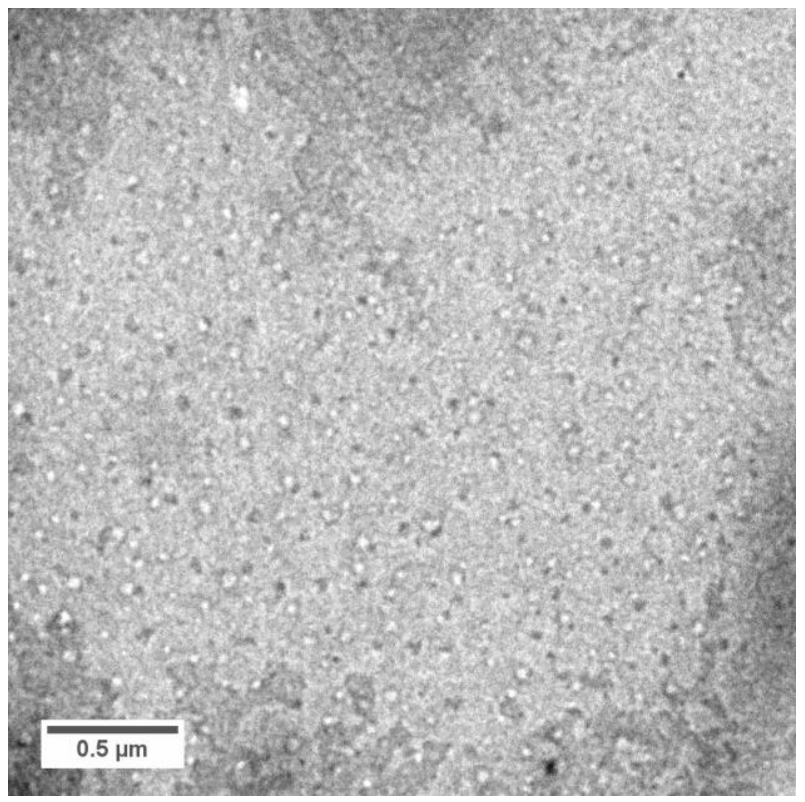

Figure S4. CryoTEM image of the PS- $b$-P4VP block copolymer after heating with $0.1 \mathrm{wt} \% \mathrm{DBD}$, showing spherical micelles. 

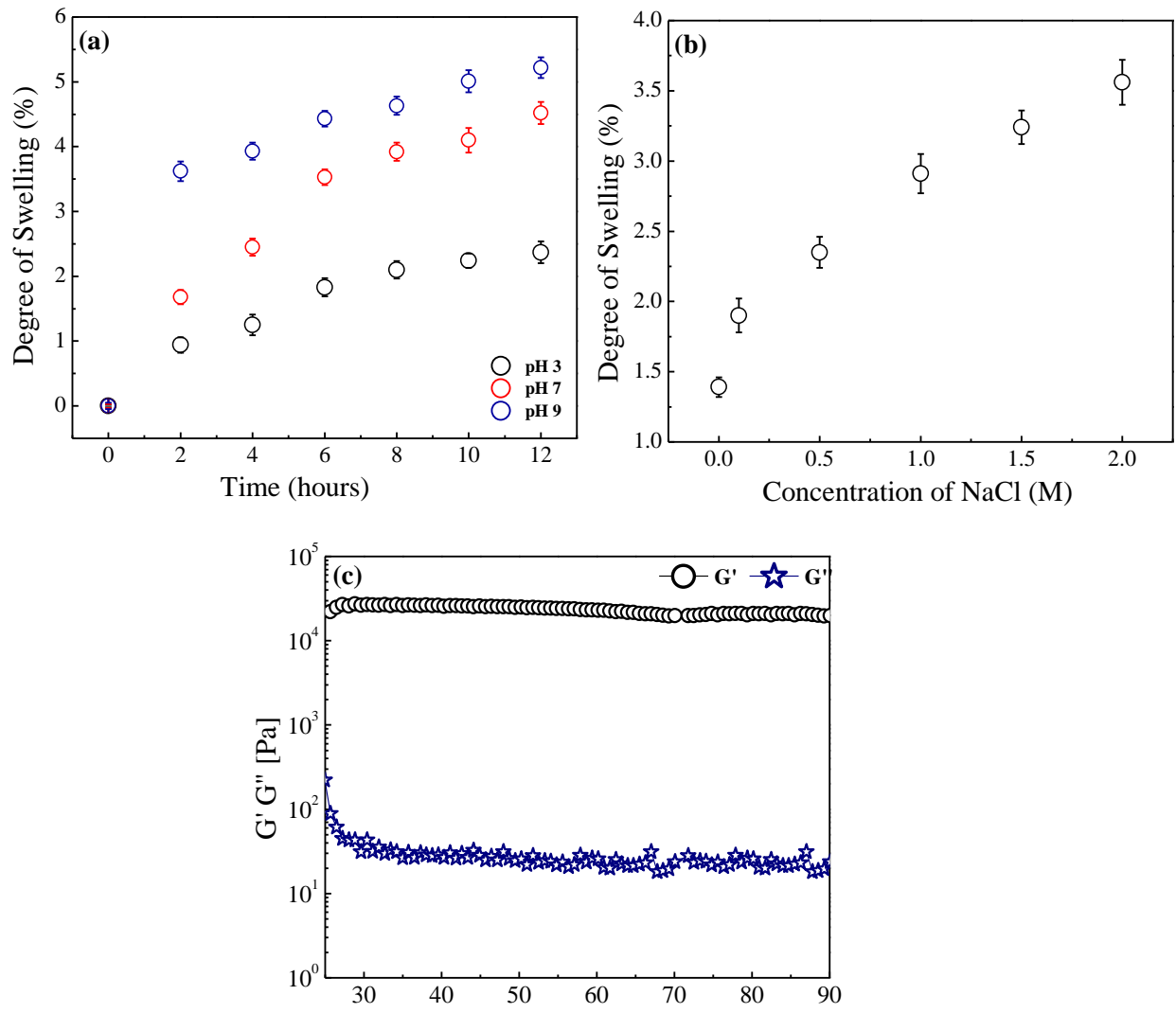

Figure S5. Stability of the PS- $b$-P4VP organogel as a function of (a) time in different $\mathrm{pH}$ (b) $\mathrm{NaCl}$ concentration, and (c) temperature.

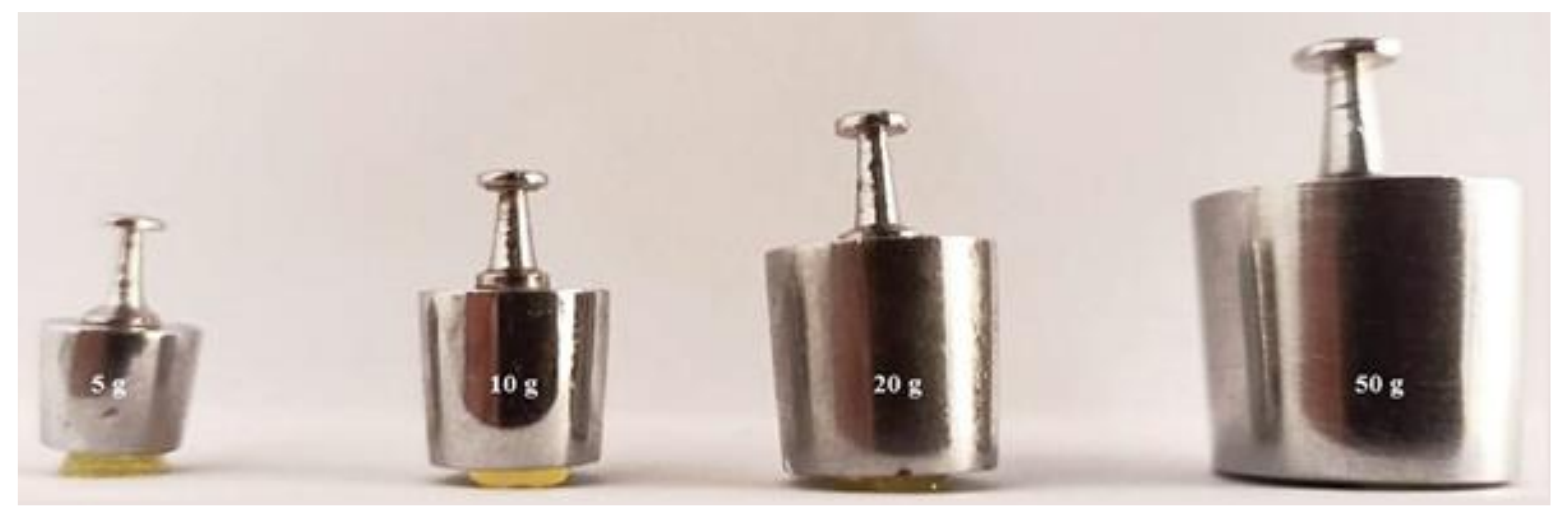

Figure S6. Mechanical stability of PS- $b$-P4VP organogel from the weight $5 \mathrm{~g}$ to $50 \mathrm{~g}$ metal bar. 

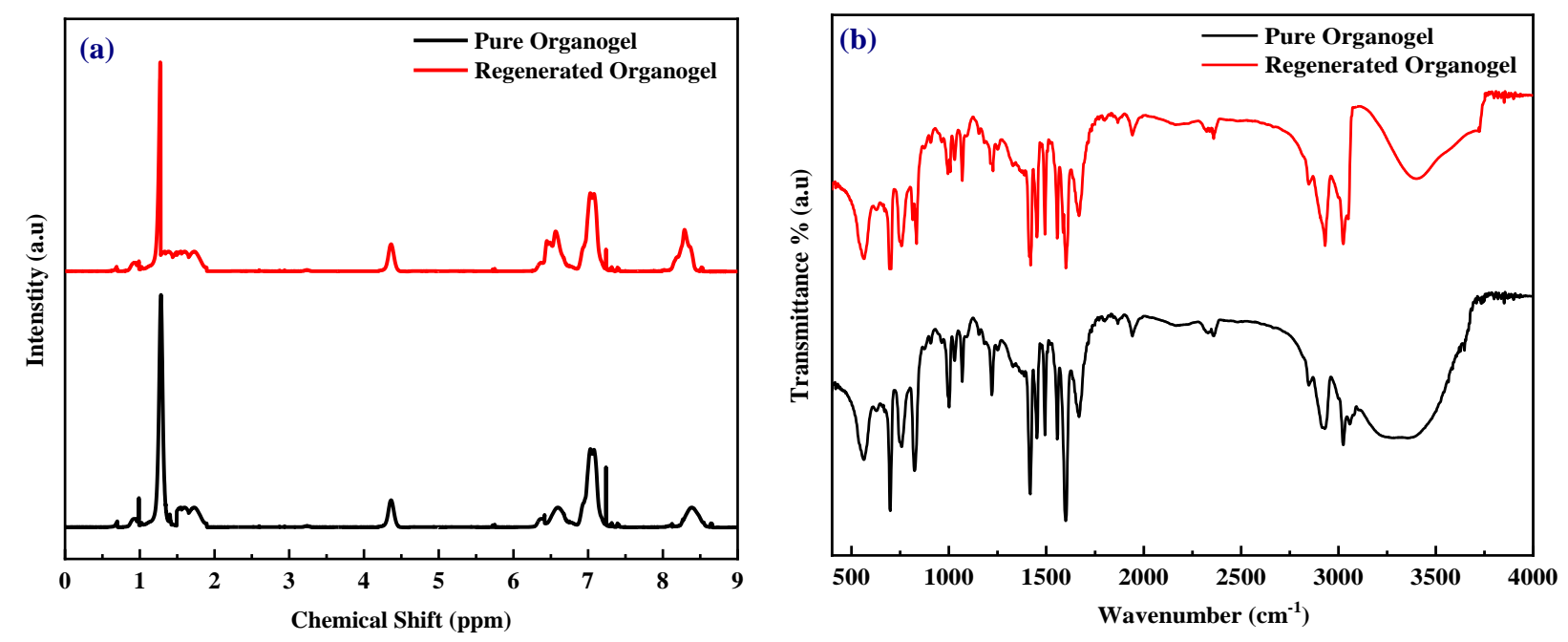

Figure S7. (a) 1H NMR and (b) FTIR spectra of the pure organogel and regenerated organogel.

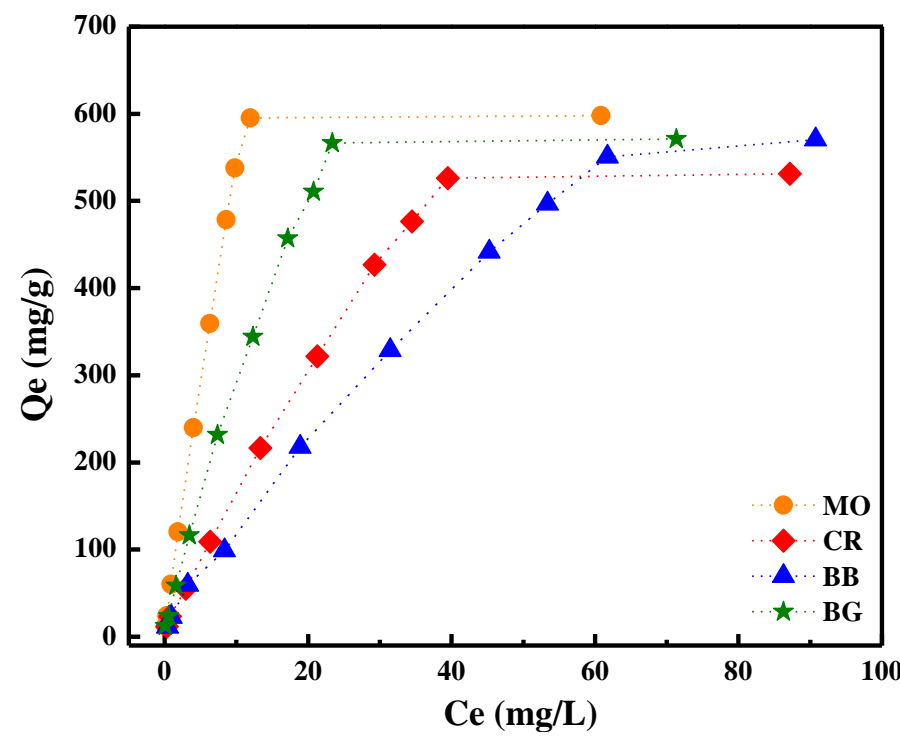

Figure S8. Equilibrium dye adsorption isotherms of the PS- $b$-P4VP organogel

The dye adsorption behaviour of the PS- $b$-P4VP organogel by means of Langmuir (eq.S1), and Freundlich isotherm (eq. S2) models.

$$
\begin{aligned}
& \frac{C_{e}}{Q_{e}}=\frac{1}{Q_{m}} \times C_{e}+\frac{1}{K_{L} Q_{m}} \\
& \ln Q_{e}=\frac{1}{n} \times \ln C_{e}+\ln K_{f}
\end{aligned}
$$

where $Q_{e}$ is the equilibrium adsorption capacity, $n$ is the Freundlich isotherm exponent (dimensionless), $Q_{m}$ is the maximum adsorption capacity, $K_{L}$ is the Langmuir Constant and $K_{f}$ is the Freundlich Constant . 

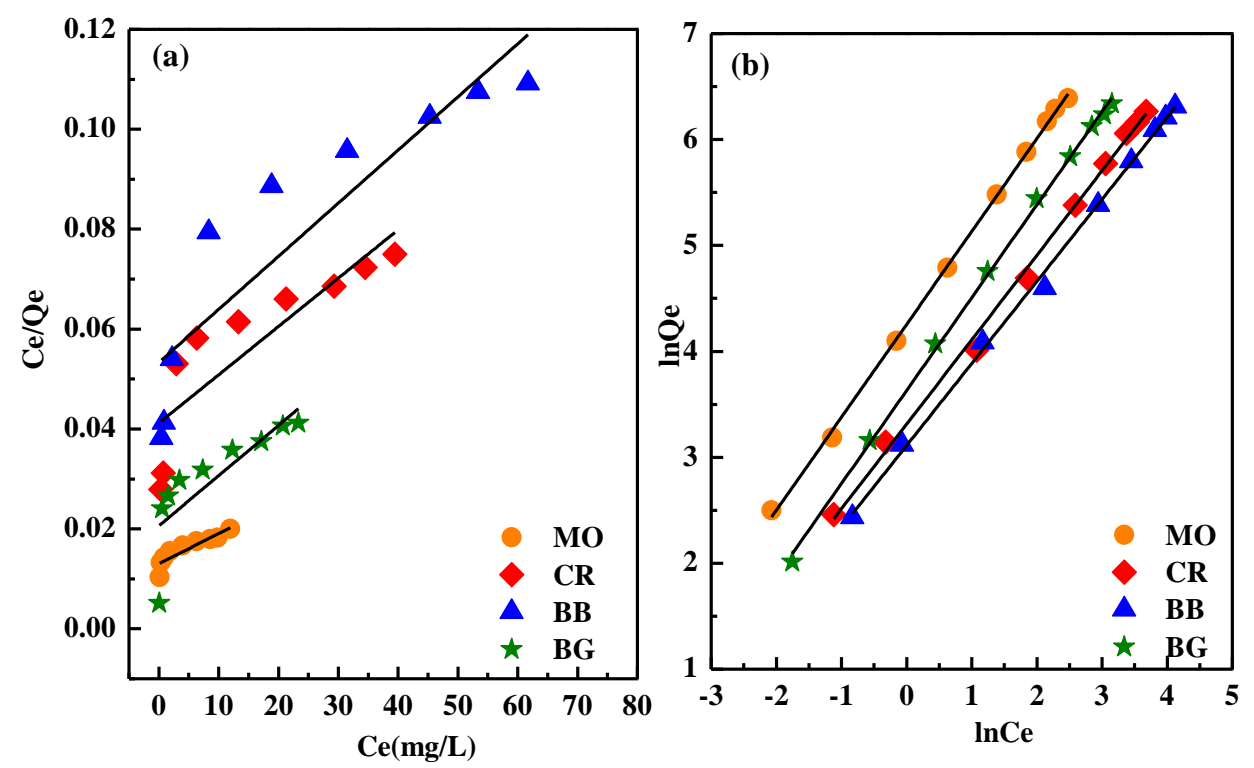

Figure S9. (a) Langmuir and (b) Freundlich isotherm models for dyes, MO, CR, BB and BG.
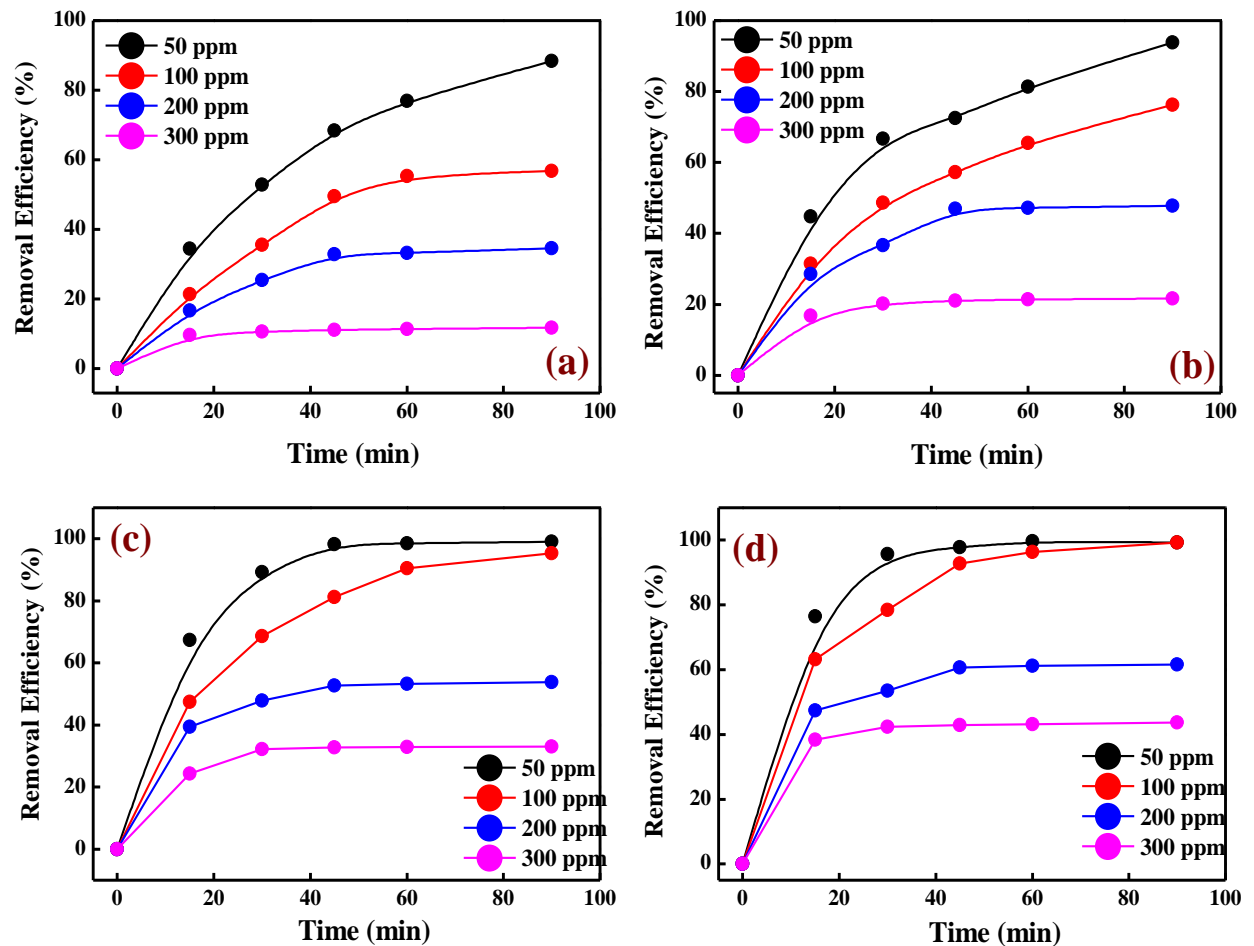

Figure S10. Effect of Contact time for different Methyl Orange dye concentrations (50, 100, 200 and $300 \mathrm{ppm}$ ) and dosage of organogel (a) $0.5 \mathrm{wt} \%$, (b) $1.0 \mathrm{wt} \%$, (c) $2.0 \mathrm{wt} \%$ and (d) $3.0 \mathrm{wt} \%$ 

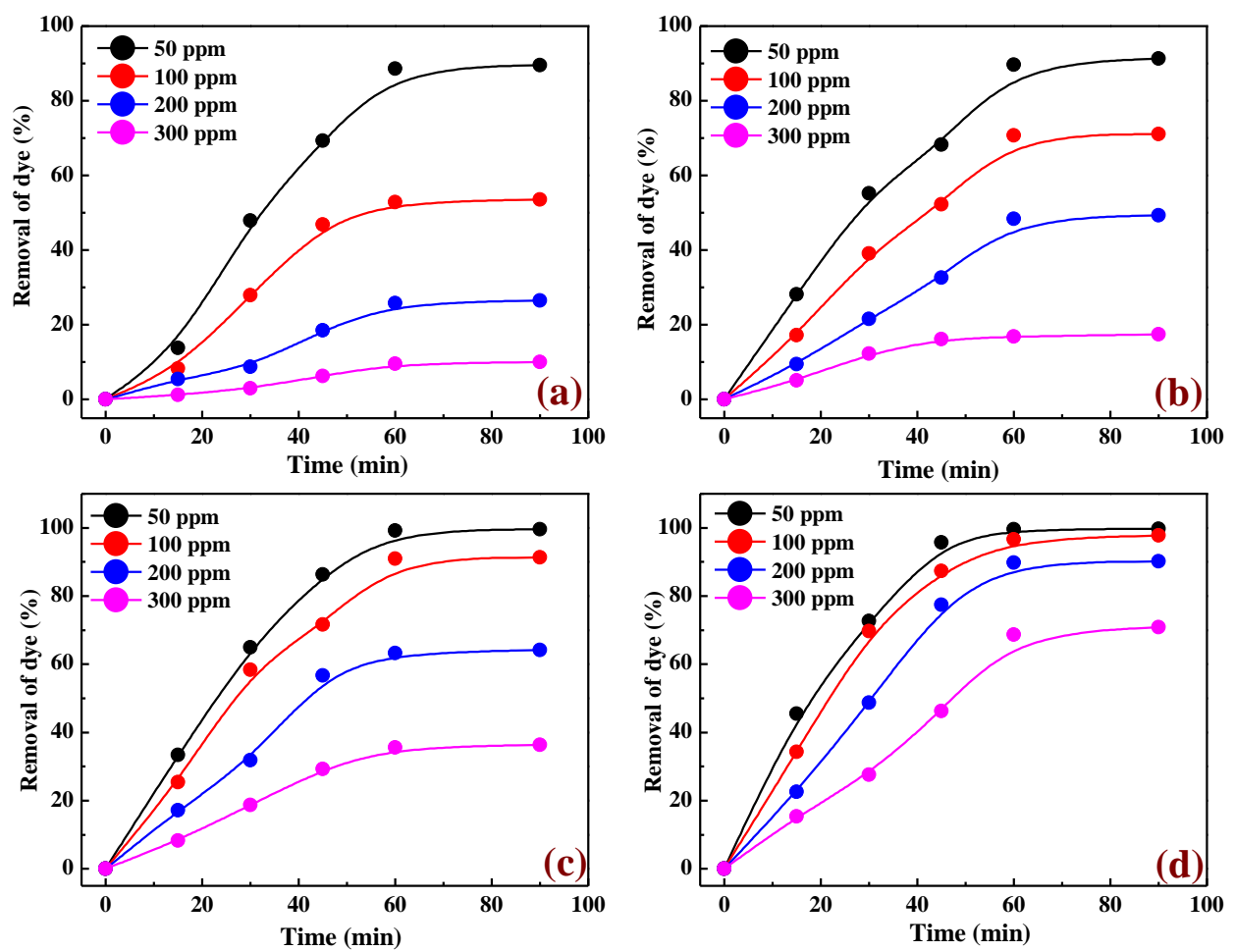

Figure S11. Effect of Contact time for different Congo red dye concentrations (50, 100, 200 and 300 ppm) and dosage of organogel (a) $0.5 \mathrm{wt} \%$, (b) $1.0 \mathrm{wt} \%$, (c) $2.0 \mathrm{wt} \%$ and (d) $3.0 \mathrm{wt} \%$.
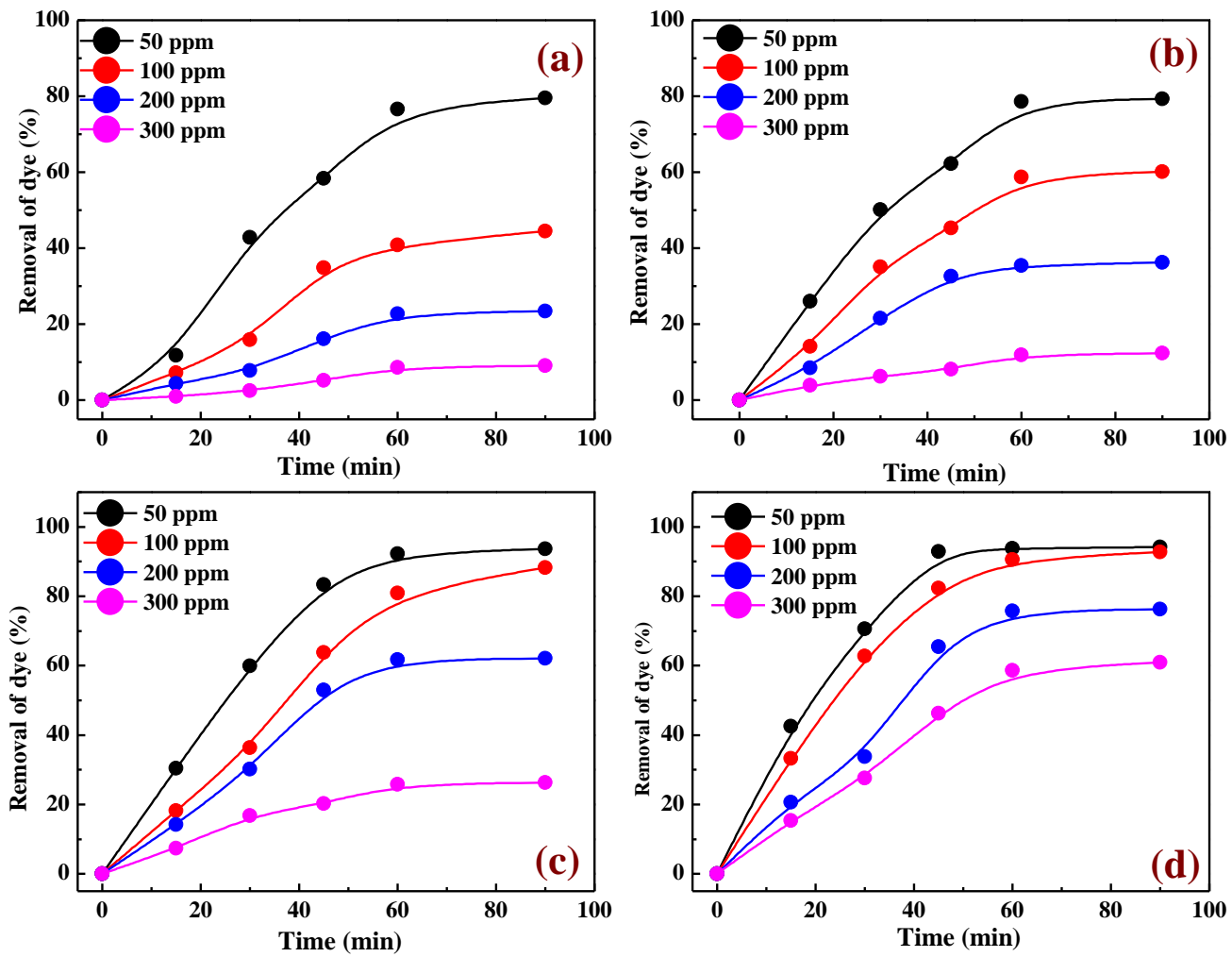

Figure S12. Effect of Contact time for different brilliant blue dye concentrations (50, 100, 200 and $300 \mathrm{ppm}$ ) and dosage of organogel (a) $0.5 \mathrm{wt} \%$, (b) $1.0 \mathrm{wt} \%$, (c) $2.0 \mathrm{wt} \%$ and (d) $3.0 \mathrm{wt} \%$. 

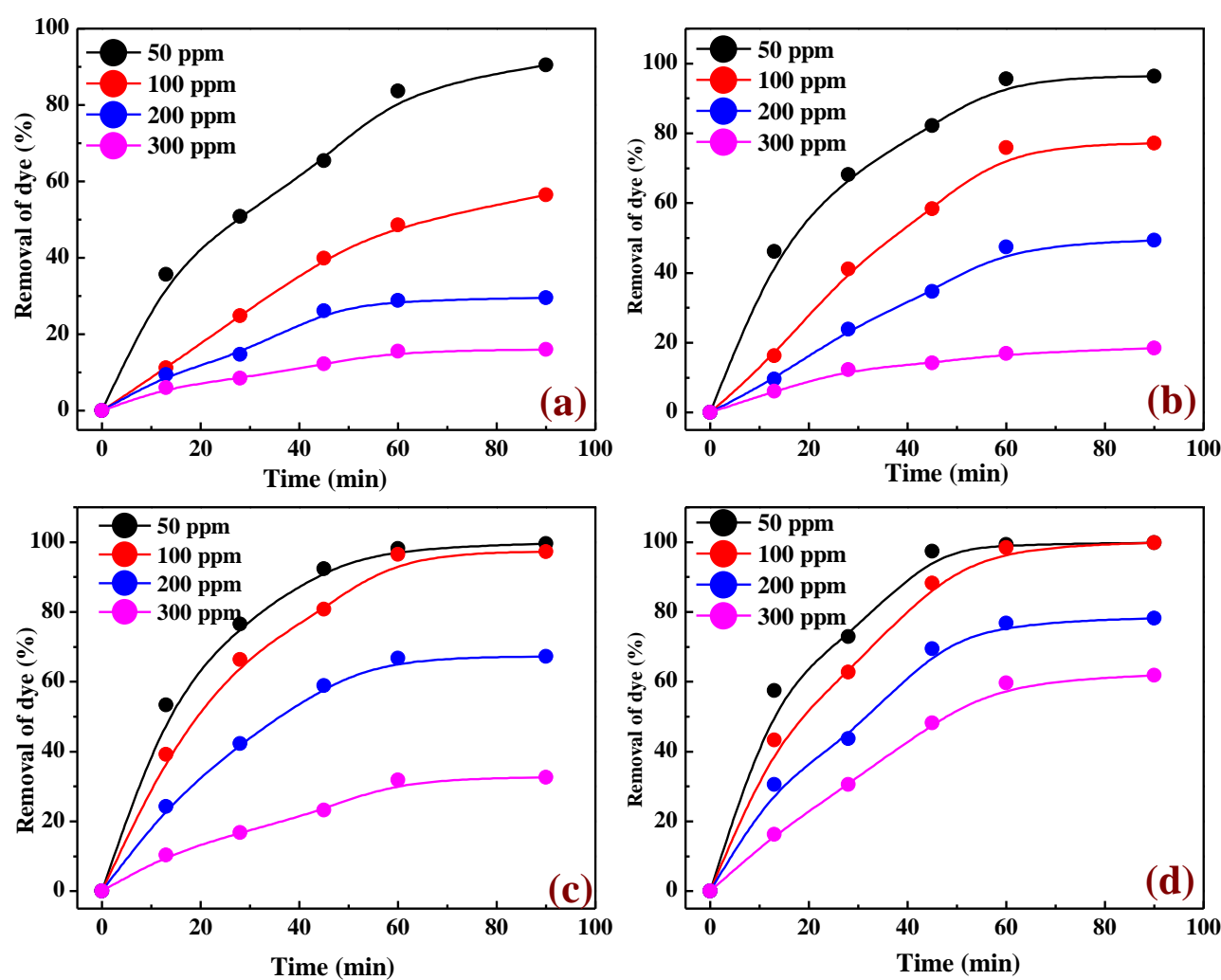

Figure S13. Effect of Contact time for different bromocresol green dye concentrations (50, 100, 200 and $300 \mathrm{ppm}$ ) and dosage of organogel (a) $0.5 \mathrm{wt} \%$, (b) $1.0 \mathrm{wt} \%$, (c) $2.0 \mathrm{wt} \%$ and (d) $3.0 \mathrm{wt} \%$ 